\title{
Productivity, taxes, and hours worked in Spain: 1970-2015
}

\author{
Juan C. Conesa ${ }^{1}$ (D) Timothy J. Kehoe ${ }^{2}$
}

Received: 8 September 2016 / Accepted: 8 July 2017 / Published online: 21 July 2017

(C) The Author(s) 2017. This article is an open access publication

\begin{abstract}
In the early 1970s, hours worked per working-age person in Spain were higher than in the United States. Starting in 1975, however, hours worked in Spain fell by $40 \%$. We find that $80 \%$ of the decline in hours worked can be accounted for by the evolution of taxes in an otherwise standard neoclassical growth model. Although taxes play a crucial role, we cannot argue that taxes drive all of the movements in hours worked. In particular, the model underpredicts the large decrease in hours in 1975-1986 and the large increase in hours in 1994-2007. The lack of productivity growth in Spain during 1994-2015 has little impact on the model's prediction for hours worked.
\end{abstract}

Keywords Dynamic general equilibrium · Hours worked · Distortionary taxes · Total factor productivity

\footnotetext{
This work has benefited from outstanding research assistance by Parisa Kamali. The authors can be reached via e-mail at juan.conesa@stonybrook.edu and tkehoe@umn.edu. The data and the explanation of all the constructed data used in this project can be accessed online at https://sites.google.com/site/ jcconesa/research and at http://users.econ.umn.edu/ tkehoe/. Earlier versions of this paper were circulated starting in August 2005. The views expressed herein are those of the authors and not necessarily those of the Federal Reserve Bank of Minneapolis or the Federal Reserve System.
}

Electronic supplementary material The online version of this article (doi:10.1007/s13209-017-0158-9) contains supplementary material, which is available to authorized users.

$凶 \quad J u a n$ C. Conesa

juan.conesa@stonybrook.edu

1 Stony Brook University, Stony Brook, NY, USA

2 Federal Reserve Bank of Minneapolis and National Bureau of Economic Research, University of Minnesota, Minneapolis, MN, USA 
JEL Classification C68 $\cdot$ E13 $\cdot$ E24 $\cdot$ H31

\section{Introduction}

What forces have driven output growth and fluctuations in Spain over the last three decades? What has been the impact of the evolution of taxes and total factor productivity (TFP) on aggregate hours worked and output? We study these questions through the lens of growth accounting and the neoclassical growth model. Our results show that the evolution of aggregate hours worked in Spain has been consistent with the evolution of taxes, whereas lack of TFP growth has had a minor impact on hours worked. A shortcoming of our model is that it fails to account for about $20 \%$ of the movements in hours worked in booms and recessions. The model, however, does account for the declining trend in hours worked over the period 1975-2015.

The methodology used is that introduced in Kehoe and Prescott (2002), following the methodology proposed in Cole and Ohanian (1999) in their study of the U.S. Great Depression. See Conesa et al. (2007) for an exposition of this methodology and an explanation of how to extend it to different model environments.

As the first step in studying growth and hours worked in Spain over the period 1970-2015, we use growth accounting to quantify the contribution of TFP, capital deepening, and aggregate hours worked for the dynamics of output per working-age person. Next, we construct a standard neoclassical growth model in which a standin household chooses hours worked, consumption, and capital holdings, taking as given the deterministic evolution of working-age population, TFP, and tax rates. This methodology provides us with a quantitative tool for identifying the relevant margins for potential candidate explanations for changes in such variables as hours worked.

A striking feature of the Spanish growth experience is the lack of TFP growth since 1994. Our exercise is silent about the reasons behind this observation. Diaz and Franjo (2016) argue that excessive investment in structures-rather than in capital equipment-accounts for much of the stagnation of TFP. Garcia-Santana et al. (2016) argue that misallocation of resources because of "crony capitalism" is responsible for this feature. Regardless of the reason for this stagnation, however, our quantitative exercise indicates that the lack of TFP growth has had only a minor impact on the evolution of aggregate hours worked.

Prior to 1975, TFP and output per working-age person moved together in Spain. (Because of data availability, we define working age to be ages 15-64; our results are not sensitive to minor changes in this definition.) After 1975, however, this has not been the case. The reason is that 1975 marked the beginning of a trend of decreasing aggregate hours worked. This trend of decreasing hours worked sharply contrasts with the U.S. experience, where hours worked per working-age person have been roughly constant. Over the period 1970-1974, hours worked per working-age person in Spain, 23.7 hours per week, were higher than those in the United States, 23.4 hours per week. Spain provides an extreme example of a general trend in European labor market dynamics. In France, for example, hours worked per working-age person have been systematically falling since the 1960s, although the decline in France has not been as steep as in Spain. 
The differences in the labor market experiences in the United States and Europe have been extensively studied. Most of the literature in this research area has focused on the impact of differences in labor market institutions. Bentolila and Bertola (1990), Blanchard and Summers (1986) and Alesina et al. (2005), among others, focus on the role of institutions and labor market restrictions. Ljungqvist and Sargent (1998) focus on the interaction between shocks and institutions. Prescott (2004), however, argues that differential taxation alone can account for the differences in the current level of aggregate hours worked between Europe and the United States.

Ohanian et al. (2008) provide a comparison across countries that are members of the Organisation for Economic Co-operation and Development (OECD) and focus mostly on the correlation between distortionary wedges on labor supply and hours worked. While we work with a theoretical framework that is similar to that of Ohanian et al. (2008), we pay more attention to the details of the aggregate growth process for the Spanish economy. In particular, our calibration is specific to the Spanish case (instead of matching some OECD average), and we compare model outcomes to data along all the relevant dimensions at every point in time to identify the specific episodes in which there are departures between data and model predictions. Besides the fact that we work with a longer time horizon, it is hard to compare our results to those in Ohanian et al. (2008) since they do not report a specific comparison of model outcomes and data for the case of Spain.

Our analysis shows that the evolution of the taxation of consumption and factor earnings can account for the secular trend decrease in hours worked observed in Spain. Of course, our exercise is silent about the distribution of aggregate hours worked within the working-age population. The quantitative exercise that we perform allows us to identify years in which data deviate from theory in a quantitatively important way. We want to identify these episodes because they suggest avenues for future research. In particular, the comparison between the model outcomes and the data reveals that in periods of rapid changes in aggregate hours worked, the model systematically underestimates the magnitude of such changes. In particular, the model fails to account for much of the large decrease in hours worked during 1975-1986 and for much of the large increase in hours worked during 1994-2007.

Our model also predicts that hours worked and output start to fall after 2009, whereas the recession had already started in 2008. Hours fall in the model because both consumption taxes and labor income taxes increase. The discrepancy between model outcomes and the data is consistent with the critique of our model that it predicts smoother movements in hours than those observed in the data. The observation that Spanish labor markets react more to shocks than in other countries is well established in the literature. Bentolila et al. (2012) attribute the differential labor market response between Spain and France during the 2008-2009 recession to the duality of Spanish labor market institutions. In particular, a large fraction of employment in Spain is covered by temporary contracts with very low hiring and firing costs. For a more detailed treatment of the nature and consequences of the Great Recession in Spain, see Jimeno and Santos (2014) and the other papers in the special issue of SERIEs on the Great Recession in Spain. 


\section{Growth accounting exercise}

Cole and Ohanian (1999) and Kehoe and Prescott (2002) have developed the great depressions methodology to detect and analyze large deviations from balanced growth behavior. They use economic theory in the form of the neoclassical growth model to guide their view of economic data. The model features an aggregate production function of the Cobb-Douglas form,

$$
Y_{t}=A_{t} K_{t}^{\alpha} L_{t}^{1-\alpha}
$$

where $Y_{t}$ is output, $A_{t}$ is total factor productivity, $K_{t}$ is capital, and $L_{t}$ is labor input. If the population grows at a constant rate, $N_{t}=\eta^{t} N_{0}$, and TFP grows at a constant rate, $A_{t}=\gamma^{(1-\alpha) t} A_{0}$, then the economy has a balanced growth path in which all quantities per working-age person grow by the factor $\gamma$, except hours worked per working-age person, which are constant.

Kehoe and Prescott (2002) rewrite the production function (1) as

$$
\frac{Y_{t}}{N_{t}}=A_{t}^{1 /(1-\alpha)}\left(\frac{K_{t}}{Y_{t}}\right)^{\alpha /(1-\alpha)}\left(\frac{L_{t}}{N_{t}}\right) .
$$

This decomposition is useful because, along a balanced growth path, where $A_{t}$ grows at a constant rate, the capital-output ratio, $K_{t} / Y_{t}$, and hours worked per working-age person, $L_{t} / N_{t}$, are constant.

Figure 1 depicts the decomposition of the growth of output per working-age person $Y_{t} / N_{t}$ in Spain over the period 1970-2015 into three factors: the productivity factor $A_{t}^{1 /(1-\alpha)}$, the capital factor $\left(K_{t} / Y_{t}\right)^{\alpha /(1-\alpha)}$, and the labor factor $L_{t} / N_{t}$. Notice that after 1975, Spain has experienced large and persistent deviations from a balanced growth path since the growth in GDP per working-age person differs from that in the productivity factor, and the capital and labor factors are not constant.

To construct Fig. 1, we assemble data on annual GDP and investment from national accounts. Real investment is current-price investment deflated by the GDP deflator. Conesa et al. (2007) explain why using current-price investment deflated by the investment deflator is only appropriate in a two-sector model in which the relative price of investment to consumption varies. We calculate the stock of capital by cumulating investment:

$$
K_{t+1}=(1-\delta) K_{t}+I_{t}
$$

where the depreciation rate $\delta$ is calibrated so that the average value of the ratio of capital consumption to GDP, $\delta K_{t} / Y_{t}$, matches its average value in the data. We need to choose an initial value for the capital stock in Eq. (3). A simple way to do this is to equate the capital-output ratio in the initial period to the average for the first decade of data,

$$
\frac{K_{1955}}{Y_{1955}}=\frac{1}{10} \sum_{t=1956}^{1965} \frac{K_{t}}{Y_{t}} .
$$

Notice that, if we have many years of data before the period in which we are interested, the choice of the initial value of capital would make little difference because of the 


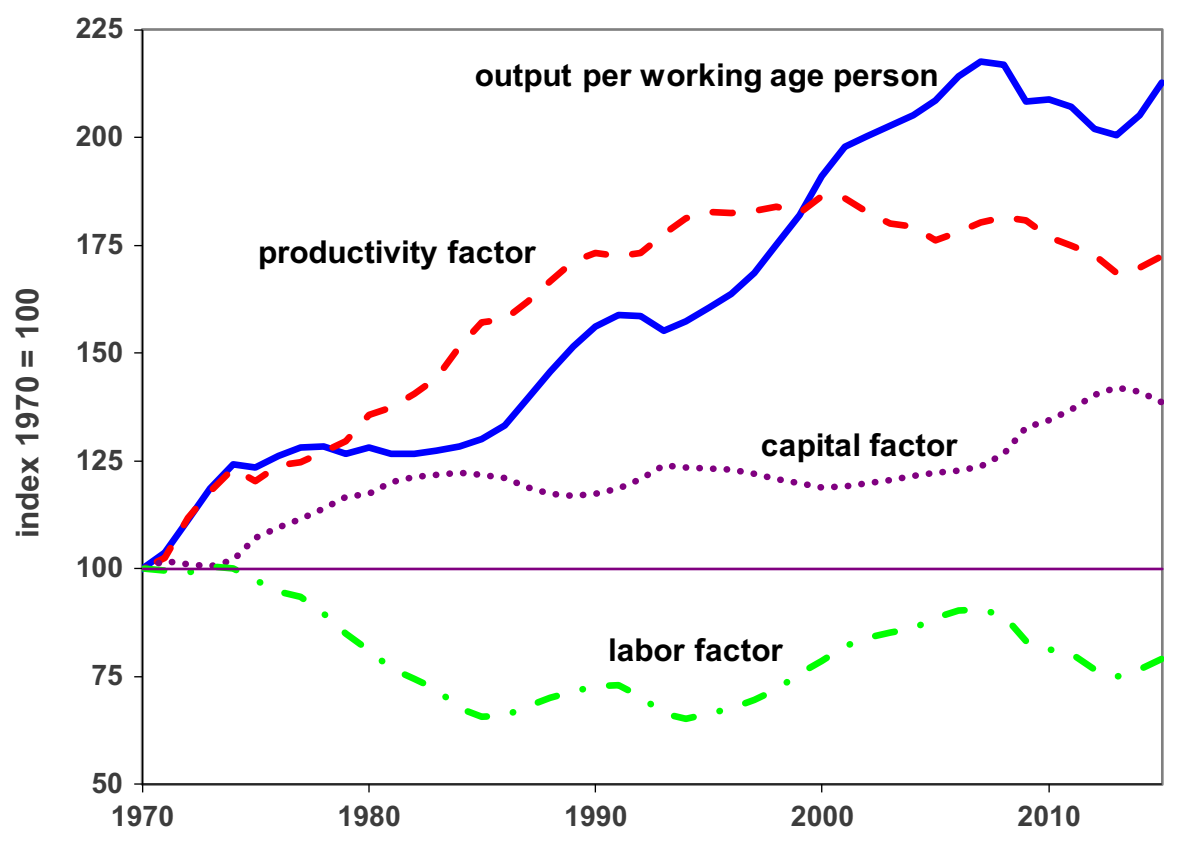

Fig. 1 Growth accounting for Spain

compounding of depreciation in the cumulation of investment (3). For the growth accounting reported in Fig. 1, we have data on investment and GDP starting in 1955. We calibrate $\delta=0.0457$. We also use national income accounts to calibrate the capital share and obtain $\alpha=0.3748$. See the online data appendix for details.

Starting in 1975, the Spanish economy diverges sharply from a balanced growth path. Output per working-age person $Y_{t} / N_{t}$ grows more slowly (if at all) than does the productivity factor $A_{t}^{1 /(1-\alpha)}$ because hours worked per working-age person $L_{t} / N_{t}$ fall sharply even though there is a sharp increase in the capital factor $\left(K_{t} / Y_{t}\right)^{\alpha /(1-\alpha)}$. Between 1974 and 1986, hours per working-age person fall by about 40\%. Over the next 10 years, hours fluctuate, and in 1994 they begin to rise until they start to fall again in 2008 .

\section{Theoretical framework}

We follow Cole and Ohanian (1999) and Kehoe and Prescott (2002) in using a simple general equilibrium growth model to match theory with data and to identify episodes where model predictions deviate from the data. The model has a stand-in household that has utility for consumption and leisure and that makes decisions on the tradeoff between labor and leisure and that between consumption and investment. There is a one-sector production technology given by the production function (1), and the economy is closed to foreign trade. The government transfers tax revenue (in excess of government consumption) to the household as a lump sum so as to balance the 
budget every period. The household has perfect foresight over the evolution of all the exogenous variables: population, taxes, government consumption, lump-sum transfers, and TFP.

The household's maximization problem is

$$
\begin{aligned}
& \max \sum_{t=1970}^{\infty} \beta^{t}\left[\gamma \log C_{t}+(1-\gamma) \log \left(N_{t} \bar{h}-L_{t}\right)\right] \\
& \quad \text { s.t. }\left(1+\tau_{t}^{c}\right) C_{t}+K_{t+1}-K_{t}=\left(1-\tau_{t}^{\ell}\right) w_{t} L_{t} \\
& \quad+\left(1-\tau_{t}^{k}\right)\left(r_{t}-\delta\right) K_{t}+T_{t} \\
& \quad K_{1970}=K_{1970}
\end{aligned}
$$

Here $N_{t}$ denotes the number of people in the working-age population in the economy, and $\bar{h}$ denotes the yearly disposable time endowment of each individual. The fiscal variables that the household sector takes as given are the taxes on consumption, on labor income, and on net capital income $\left(\tau_{t}^{c}, \tau_{t}^{\ell}, \tau_{t}^{k}\right)$, and the transfers $T_{t}$. The choice variables are sequences of aggregate consumption levels $C_{t}$, aggregate capital stocks $K_{t}$, and levels of aggregate hours worked $L_{t}$.

In each period, the resource constraint is

$$
C_{t}+K_{t+1}-(1-\delta) K_{t}+G_{t}=A_{t} K_{t}^{\alpha} L_{t}^{1-\alpha}
$$

The government budget constraint is

$$
\tau_{t}^{c} C_{t}+\tau_{t}^{\ell} w_{t} L_{t}+\tau_{t}^{k}\left(r_{t}-\delta\right) K_{t}=G_{t}+T_{t}
$$

The familiar conditions for cost minimization and zero profits are

$$
w_{t}=(1-\alpha) A_{t} K_{t}^{\alpha} L_{t}^{-\alpha}
$$

and

$$
r_{t}=\alpha A_{t} K_{t}^{\alpha-1} L_{t}^{1-\alpha}
$$

Because the taxes on consumption — but not those on labor or capital—are indirect taxes that enter into the market prices that the household pays for consumption, we must modify our definition of GDP in the model, measuring it as statistical agencies do:

$$
Y_{t}=A_{t} K_{t}^{\alpha} L_{t}^{1-\alpha}+\tau_{t}^{c} C_{t} .
$$

This modification implies that the productivity term in the model, $A_{t}$ in Eq. (10), differs from total factor productivity in the growth accounting exercise in the previous section. In particular, we use a measure of TFP of GDP at factor prices:

$$
A_{t}=\frac{Y_{t}-\tau_{t}^{c} C_{t}}{K_{t}^{\alpha} L_{t}^{1-\alpha}},
$$

whereas the TFP measure in the growth accounting exercise is TFP of GDP at market prices. 
It is worth noting that the concept of GDP at factor prices that we use in the model, $Y_{t}-\tau_{t}^{c} C_{t}$, is not precisely the measure of GDP at factor prices, or GDP at factor cost, found in Spain's national income statistics. The reasons are twofold. First, our measure fails to subtract out of GDP at market prices all indirect taxes, in particular tariffs on imports and indirect taxes on purchases of intermediate goods that were prevalent before Spain's 1986 value added tax reform. Second, since we are using a closed economy model, our measure of consumption includes the trade balance.

To be precise, we could refer to the productivity term $A_{t}$ in Eq. (11) as TFP of GDP at factor prices, but we refer to it simply as TFP in the rest of this paper with the warning that it differs from the TFP in the growth accounting section, which is TFP of GDP at market prices.

Our benchmark specification implies that all tax proceeds in excess of government consumption are rebated to the household in lump sum. There are two reasons for doing so: first, because we are measuring marginal tax rates instead of average tax rates, a lump-sum rebate makes our taxes progressive; and second, because a very large fraction of the government's budget is used to finance transfers directly. In fact, looking at the composition of government expenditure, we find that the sum of pensions, health care, unemployment insurance, and education in Spain amounts to more than half of the government outlays. Our benchmark specification implies that all of government consumption, as opposed to government transfers, is a waste, or equivalently it finances some public good that enters utility in a separable form. Notice that this specification is not neutral in determining the implication of taxes for hours worked. Assuming instead that all government revenues are rebated to the household-that is, making $G_{t}=0$ in the government budget constraint-would imply that there is no income effect of taxation, making hours worked fall even more when households are faced with higher taxes.

It is worth pointing out that we can ignore government debt because the model exhibits Ricardian equivalence with respect to the timing of transfers. In particular, the existence of government debt would only change the timing of transfers, leaving all other variables unaffected. Of course, the model does not exhibit complete Ricardian equivalence since taxes are distortionary, but this only means that the timing of taxes matters, not the timing of borrowing, lending, and transfers.

\section{Evolution of fiscal variables}

We obtain estimates of effective marginal tax rates using a methodology similar to that of Mendoza et al. (1994). Our methodology differs from theirs in two respects: First, we attribute a fraction of households' nonwage income to labor income to be consistent with our estimate of the capital share. Second, we account for tax progressivity by adjusting average income taxes by the ratio of the marginal income tax to the average income tax from an estimated tax function [following Gouveia and Strauss (1994)]. The estimated tax for the Spanish economy in the 1990s suggests that the marginal income tax is 1.8 times the average income tax, and this is the adjustment factor that we use. See the online data appendix for details on the use of this adjustment factor. 


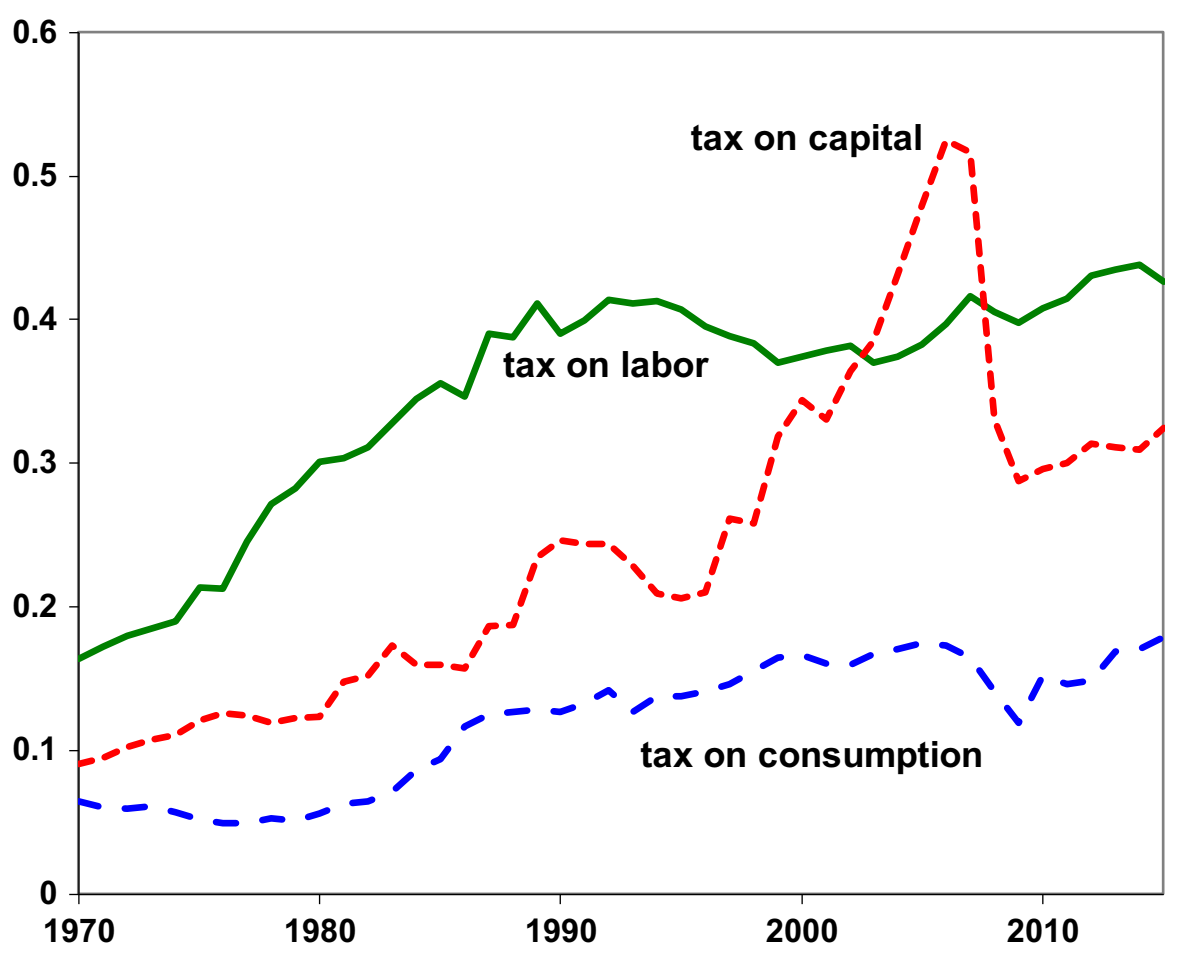

Fig. 2 Evolution of effective marginal tax rates

Our estimates show a substantial increase in taxation of both the income of factors of production and consumption. Regarding the taxation of capital income our estimates generate a very large spike in this taxation. The reason for this large spike is that during the boom prior to the recession tax revenues from corporate income taxes grew faster than net capital income in the national accounts, while there was a large drop in corporate tax revenues with the recession. Corporate tax revenues as a share of net capital income grew from $7 \%$ in 1994 to $29 \%$ in 2007.

Estimating effective marginal tax rates requires that we take into account the progressivity of income taxes. Taxation of labor earnings can be decomposed into income taxation and payroll taxes (which are mostly social security contributions that are roughly proportional). Since the relevant data for our model in terms of the distortionary implications are the marginal, and not the average, tax rates, we scale up by $83 \%$ the taxation of households' income in order to compute effective marginal tax rates. This adjustment is constant over time and only affects the levels of tax rates, not its evolution over time, which is what matters in our model. Figure 2 reports our estimates of marginal tax rates.

The taxes in our model do not account for all of the taxes in the Spanish economy. In addition to income taxes on labor income and capital income and indirect taxes on consumption, there are tariffs on imports and indirect taxes net of subsidies on firms. A simple way in which we could account for these additional taxes would be to include them in the taxes on consumption: 


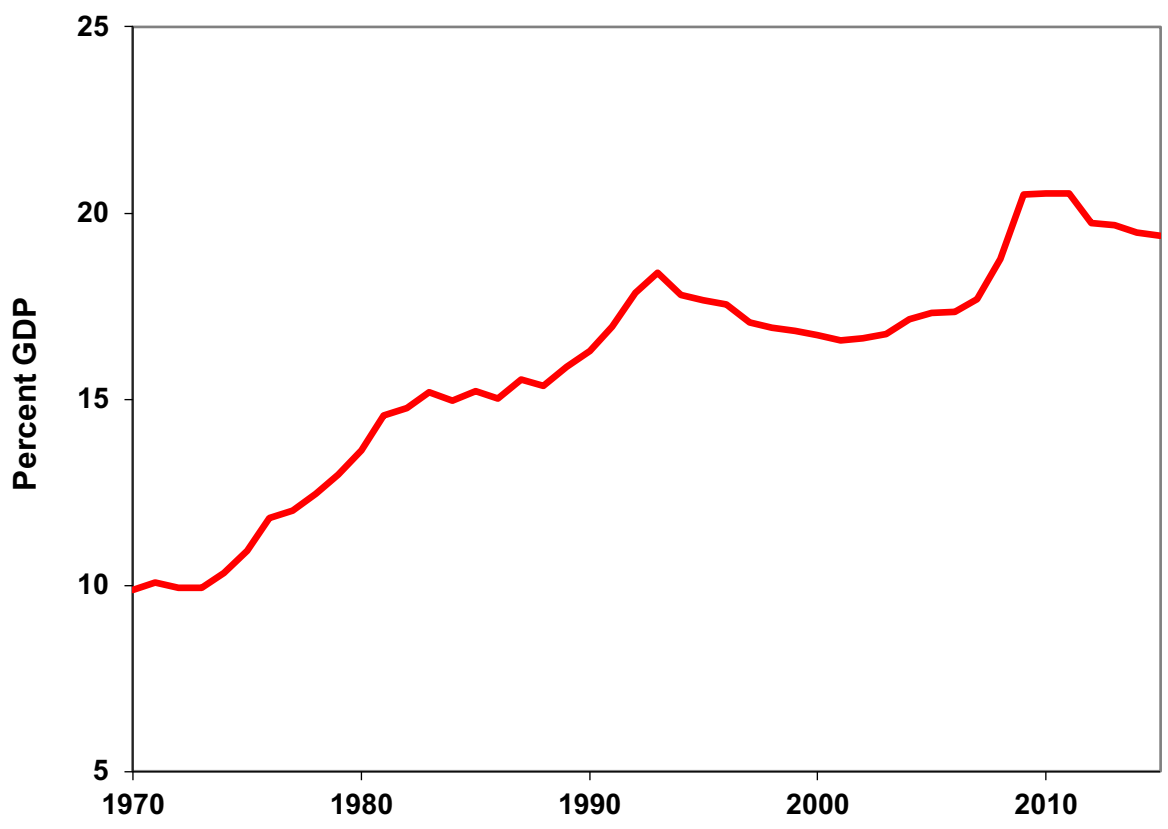

Fig. 3 Evolution of government consumption

$$
\tau_{t}^{c}=\frac{Y_{t}-Y_{t}^{F}}{C_{t}} .
$$

Here $Y_{t}^{F}$ is GDP at factor prices from the national accounts, which nets out of GDP at market prices not only indirect taxes on consumption but also tariffs on imports and indirect taxes paid by firms. In this case, to compute TFP of GDP at factor prices as in Eq. (11), we replace $Y_{t}-\tau_{t}^{c} C_{t}$ with $Y_{t}^{F}$. Recalibrating the model in this manner has very little impact on our results since more than $80 \%$ of all indirect taxes in Spain over the period 1975-2015 were taxes on consumption, and the evolution of all indirect taxes followed that of consumption taxes.

Figure 3 reports the evolution of government consumption, showing how it has doubled its size as a share of GDP, with most of the increase occurring between 1974 and 1992.

\section{Calibration and numerical experiments}

In the numerical experiments that we perform, our model determines the evolution of the endogenous variables, given the initial capital stock in 1970 as measured in the data. The endogenous variables react to the evolution of the exogenous variables, which are the evolution of TFP of GDP at factor prices, the evolution of the workingage population, and the evolution of tax rates as measured in the data. 
To run our numerical experiments, we need to make assumptions about the evolution of exogenous variables after 2015. We assume that TFP grows at the rate at which it grew in the years immediately prior to the recession, 2003-2008. Figure 1 shows that TFP of GDP at market prices did not grow from 1995 until 2015, and the behavior of TFP at factor prices in Eq. (11) is almost identical. Consequently, we are assuming no TFP growth after 2015. We assume that the working-age population is constant after 2015, even though projections by the United Nations indicate that the working-age population in Spain will decline. Finally, we assume that tax rates stay constant at their 2015 level. None of our results seem to depend critically on these assumptions, since most of the model predictions are driven by the static labor supply condition. Given our assumptions on the evolution of the exogenous variables, we calculate the equilibrium up to the terminal date of 2044 assuming that the equilibrium has converged to a steady state by that date. Conesa et al. (2007) provide a detailed explanation of the computational procedure and a MATLAB program for implementing it.

Next, we need to assign values to all the parameters in the model. To determine the value of the disposable time endowment of individuals, $\bar{h}$, we assume that each adult has a time endowment of 100 hours a week. We choose the depreciation rate $\delta$ so that the ratio of capital consumption to GDP coincides with the average value observed in the data over the period 1970-2015. Calculating

$$
\frac{\delta}{46} \sum_{t=1970}^{2015} \frac{K_{t}}{Y_{t}}=0.139,
$$

we obtain $\delta=0.046$. We estimate the capital share in Spain to be 0.375 using the same national accounting data as those used for the growth accounting exercise and for the estimation of the marginal tax rates.

To calibrate the preference parameters, we use the first-order conditions from the household problem (5) and data observations for the period 1970-1974. Deriving the first-order conditions with respect to $C_{t}$ and $L_{t}$ and rearranging, we can write the values of the preference parameters as functions of data observations:

$$
\begin{aligned}
& \beta=\frac{\left(1+\tau_{t+1}^{c}\right) C_{t+1}}{\left(1+\tau_{t}^{c}\right) C_{t}\left(1+\left(1-\tau_{t}^{k}\right)\left(r_{t}-\delta\right)\right)} \\
& \gamma=\frac{\left(1+\tau_{t}^{c}\right) C_{t}}{\left(1+\tau_{t}^{c}\right) C_{t}+\left(1-\tau_{t}^{\ell}\right) w_{t}\left(N_{t} \bar{h}-L_{t}\right)} .
\end{aligned}
$$

Using conditions (14) and (15), we can compute annual observations for the parameters $\beta$ and $\gamma$. The parameters we assign to our economy are the averages over the period 1970-1974, $\beta=0.952$ and $\gamma=0.280$.

Notice that we have calibrated the technology parameters - the depreciation rate $\delta$ and the labor share $\alpha$-using data from the entire period 1970-2015, whereas we have calibrated the behavioral parameters - the discount factor $\beta$ and the consumption share $\gamma$-using only data for 1970-1974. Changing the period used for calibrating the technology parameters has negligible effects on our results, whereas changing the period for calibrating the behavioral parameters has significant effects on the results. Our benchmark calibration follows Bergoeing et al. (2002) in choosing behavioral 
parameters to match household behavior in a period in which we are not interested, in this case 1970-1974, and we test the model by seeing how well it matches behavior in the period in which we are interested, in this case 1975-2015. We find that our results for real GDP per working-age person and the capital-output ratio improve significantly when we recalibrate the behavioral parameters to match behavior over 1970-2015 but that our results on hours worked per working-age person do not change in any significant way.

\section{Results for the benchmark economy and the counterfactual with constant taxes}

Given that our goal is to quantify the implications of the evolution of taxes on hours worked, our principal exercise is to compare our benchmark model results with a counterfactual in which we hold tax rates and government consumption constant at their initial levels. We require that government consumption grow by a factor that is a product of the growth factor of population and the growth factor of productivity, so that a balanced growth path would be possible. In particular, in the counterfactual we hold the tax rates constant at their average rates over 1970-1974 and government consumption constant at its average level over the same period. Alternatively, we could have held government consumption as a fraction of GDP constant without changing the results in any important way.

Figure 4 shows the evolution of GDP per working-age person in the data, in the benchmark model, and in the counterfactual model with constant taxes and constant government consumption. Notice that the benchmark model does reasonably well until the late 1980s, but it fails to predict the increase in output afterward. The model with constant taxes does better in predicting the increase in output over the whole period but overpredicts the increase in the 1980s and 1990s.

Figures 5 and 6 show the evolution of the capital-output ratio and hours worked per working-age person. In Fig. 5, we see that the benchmark model does a poor job in capturing the increase in the capital-output ratio.

In Fig. 6, the data on hours worked show larger fluctuations relative to the predictions of the benchmark model, both when hours reach their minima in 1985 and 1994 and when they reach their maximum in 2007. Notice, however, that the benchmark model does a far better job in capturing the decline in hours worked from 1974 to 2015 than the model with constant taxes: In the data, hours worked per working-age person fall by $21.0 \%$ over this period, whereas in the benchmark model, they fall by $27.7 \%$. In contrast, in the model with constant taxes, hours worked per working-age person fall by only $11.7 \%$.

We see that two reasons explain why the model with constant taxes does a better job in capturing the average growth in GDP per working-age person over the period 19742015 than does the benchmark model: First, the model with constant taxes does a better job in capturing the capital deepening that starts in the 1980s. Second, the model with constant taxes accounts for more output growth because it does not account for the drop in hours worked. The first reason in the model with constant taxes is compatible with 


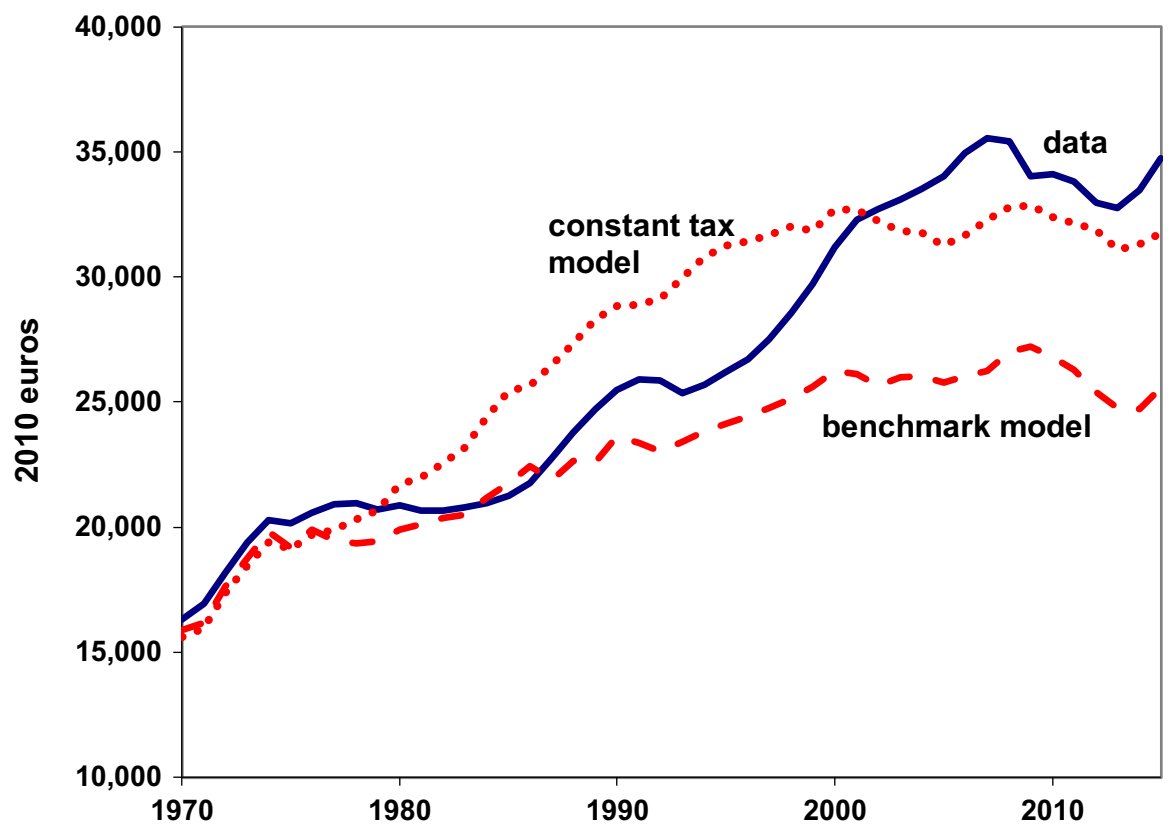

Fig. 4 GDP per working-age person in benchmark model

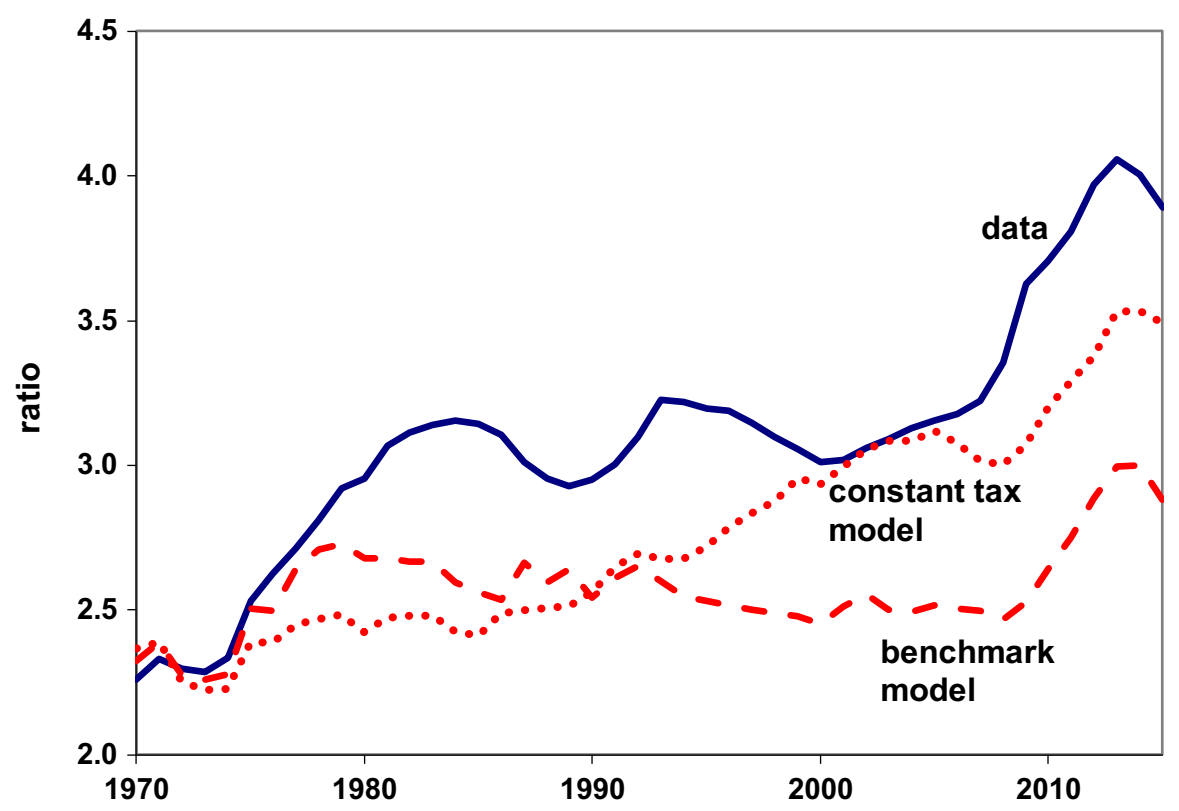

Fig. 5 Capital-output ratio in benchmark model 


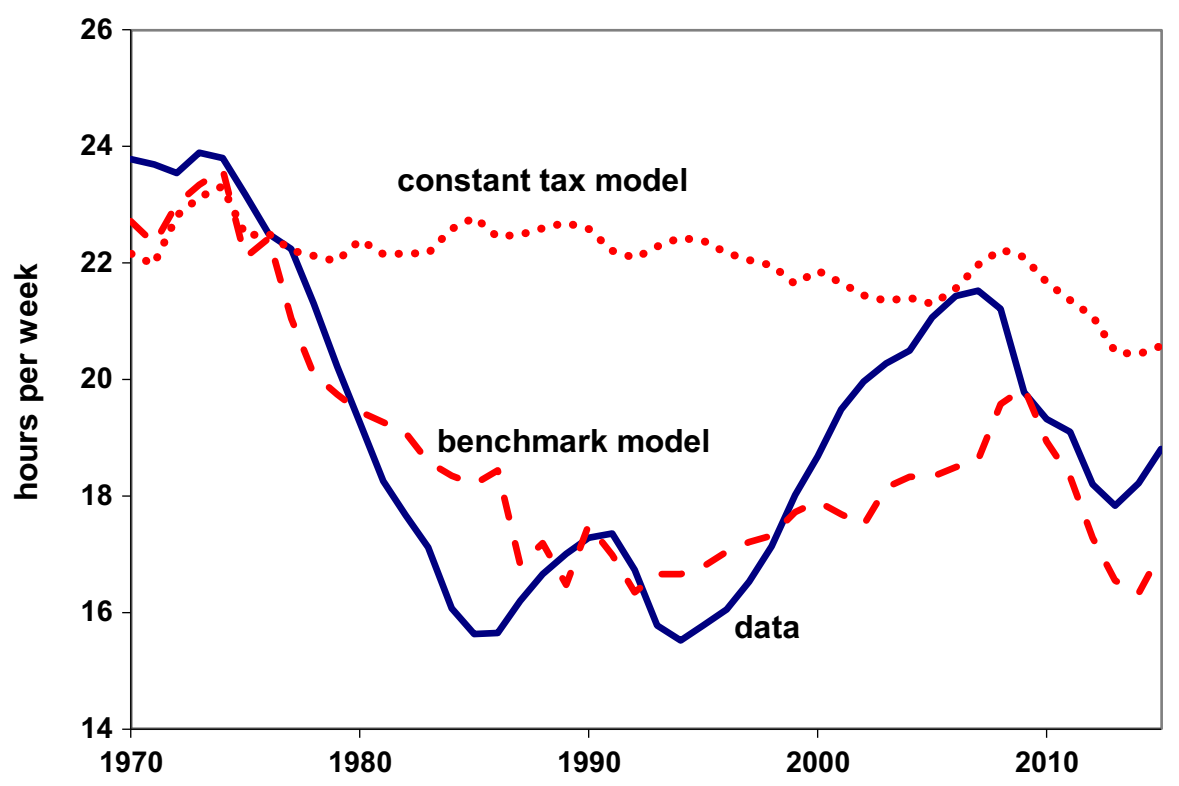

Fig. 6 Hours worked per working-age person in benchmark model

the data but leaves unanswered the question of why the capital-output ratio increased as capital income taxes were increasing.

Overall, the benchmark model — the model with increasing taxes and government consumption-does a better job in accounting for the movements in hours worked in Spain than does the model with constant taxes and government consumption. It fails to account for economic growth because it fails to account for the capital deepening that occurred in Spain starting in the 1980s.

\section{Sensitivity to recalibration of behavioral parameters}

Our methodology allows us to identify the reasons for the failure of the benchmark model to account for its poor performance in tracking the growth of real GDP per working-age person in Spain in Fig. 4. We use Eqs. (14) and (15) to recalibrate the behavioral parameters $\beta$ and $\gamma$ using data for the entire period 1970-2015. We obtain a discount factor of $\beta=0.973$ — which implies substantially less discounting than the discount factor calibrated to 1970-1974 data, $\beta=0.952$ - and a consumption share of $\gamma=0.269$ - which implies a shift in utility to favoring more leisure compared to the consumption share calibrated to 1970-1974 data, $\gamma=0.280$.

When we redo the numerical experiments in the previous section with the behavioral parameters recalibrated to 1970-2015 data, we find that the model with changing taxes and government consumption performs far better than does the model calibrated to 1970-1974 data. Figure 7 shows the improved performance of the model in capturing the growth of real GDP per working-age person. Notice, however, that the model fails to capture the boom in 2000-2007. This is worth more study. Figure 8 shows the 


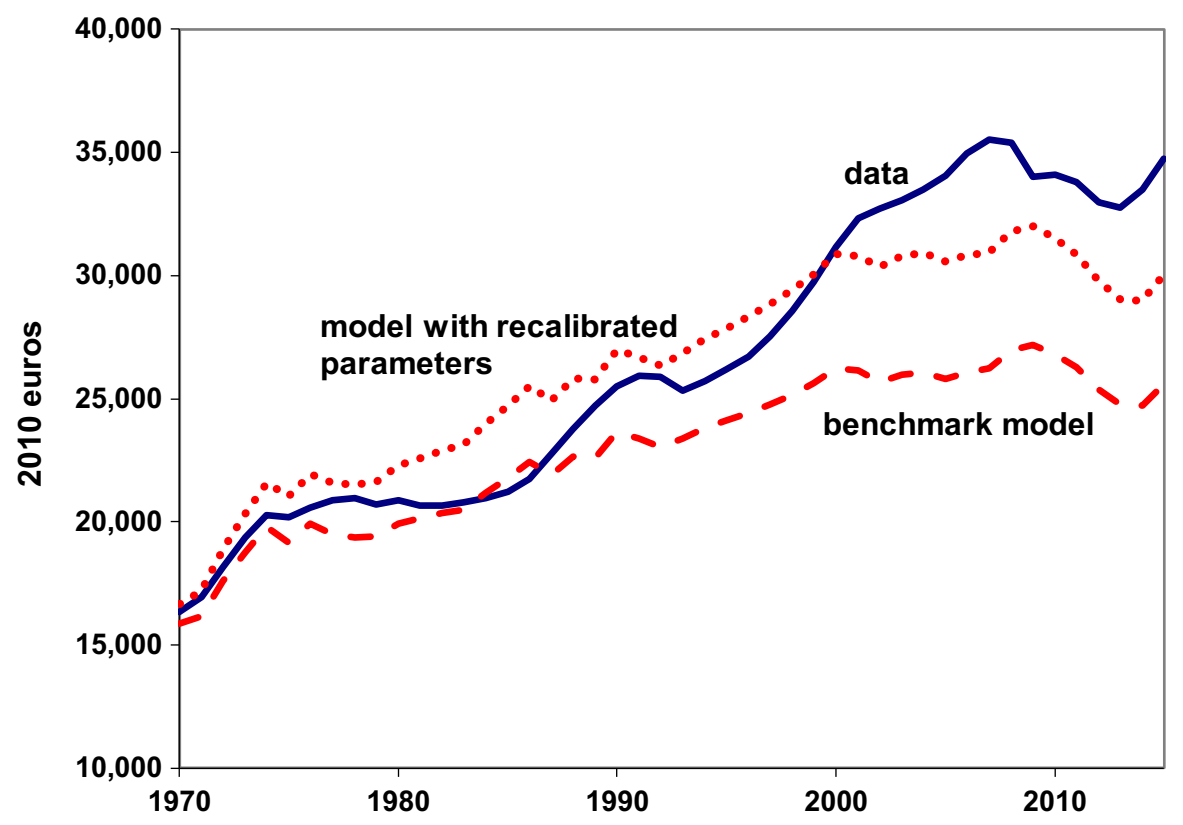

Fig. 7 GDP per working-age person with recalibrated parameters

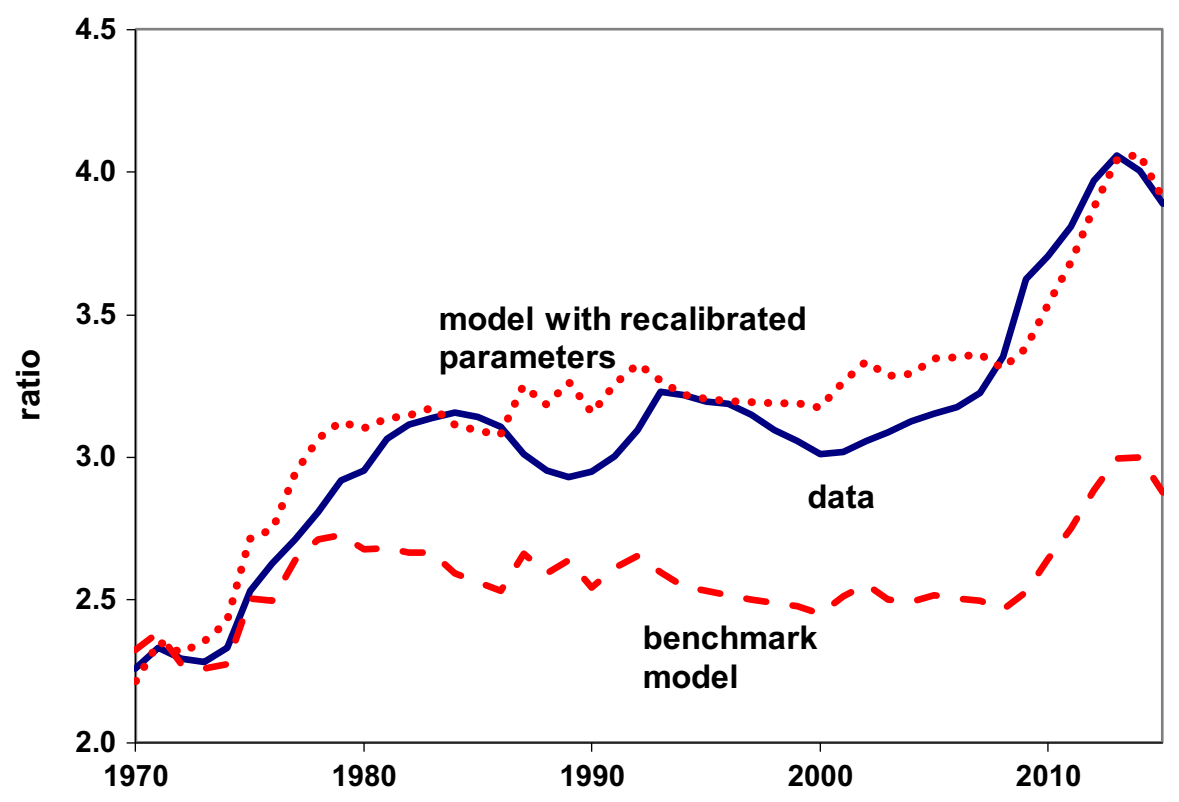

Fig. 8 Capital-output ratio with recalibrated parameters

improved performance of the model in capturing the capital deepening that occurred in Spain from the 1980s onward. Figure 9 shows that the model's results for hours worked change very little. 


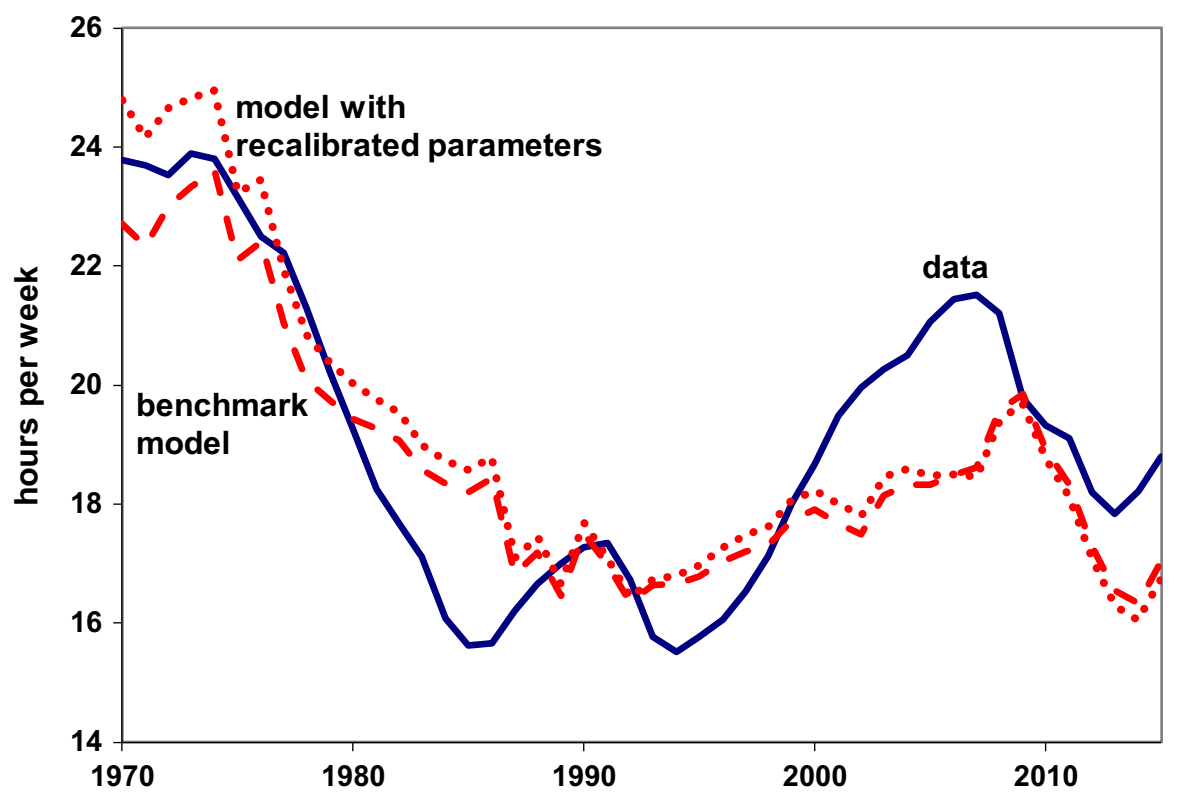

Fig. 9 Hours worked per working-age person with recalibrated parameters

Kehoe and Prescott (2002) regard the behavioral parameters $\beta$ and $\gamma$ as capturing not only the preferences of households but also, in a reduced form way, institutions and policies in the Spanish economy that affect investment markets in the case of $\beta$ and labor markets in the case of $\gamma$. Following their approach, we interpret the large change in $\beta$ as incorporating changes in institutions and policies affecting investment markets in Spain. The results in Figs. 4 and 5 suggest that a large part of these changes in institutions and policies occurred in the 1980s. Obvious candidates for these changes are the 1986 integration of Spain into what was then the European Community and the accompanying financial liberalization. Kehoe and Prescott's (2002) methodology —like the wedges methodologies of Mulligan (2005) and Chari et al. (2007)_allow us to identify where and when important policy changes have occurred and point to directions in which more general equilibrium modeling is needed. The large change in $\beta$ suggests the need for an open economy model that is capable of modeling the large capital inflows that followed Spain's integration into the European Community. One such modeling exercise is that of Fernandez de Cordoba and Kehoe (2000).

It is worth pointing out that, as Fig. 1 shows, capital deepening in Spain actually started in 1975. It is possible that some of the increase in $\beta$ can be ascribed to changes in institutions and policies that followed the change in political regime initiated with the death of the dictator Francisco Franco. We could also look for changes in institutions and policies that affect labor markets to account for the drop in the consumption share $\gamma$, but the change in $\gamma$ does not have a major impact on the results in Figs. 7, 8 and 9.

Given the success of the model with recalibrated parameters in capturing the increase in output and the capital deepening in Spain, we employ the strategy of calibrating the behavioral parameters $\beta$ and $\gamma$ using data for the entire period 1970-2015. 
In terms of the methodology of Kehoe and Prescott (2002), this means that we are implicitly incorporating changes in institutions and policies that affected investment markets and, to a lesser extent, labor markets, over the period 1975-2015.

\section{Sensitivity to the choice of labor supply elasticity}

Labor economists typically measure the responsiveness of labor supply to variation in after-tax wages using the Frisch elasticity, the elasticity of labor with respect to the after-tax wage keeping the marginal utility of income constant. In our benchmark economy, with a utility function that is separable in consumption and leisure in the stand-in household's problem (5), this elasticity is

$$
\frac{u_{\ell}}{L u_{\ell \ell}}=\frac{N_{t} \bar{h}-L_{t}}{L_{t}} .
$$

In the 1975-2015 Spanish data that we study, the average number of hours worked per working-age person is 18.6 hours per week, which leaves 81.4 hours per week for leisure. This implies that the Frisch elasticity of labor supply in our model is about 4.3, which is a large value compared to many estimates in the literature.

Considerable controversy surrounds the issue of what is the best specification of preferences for leisure and what is the most plausible labor supply elasticity. For example, Alesina et al. (2005) argue that Prescott's (2004) results depend on an implausibly high elasticity of labor supply relative to microeconometric estimates based on the variation of working hours with respect to the wages of prime-age employed males. Their criticism could also be applied to our exercise.

Notice, however, that in both Prescott's work and ours, the stand-in household makes decisions for the aggregate economy. Therefore, the solution to the household's problem should embed the participation decisions of individuals. For example, young workers decide when to enter the labor market, workers decide when to move into and out of the labor market in response to changes in households' circumstances, old workers decide when to retire. Incorporating this sort of decision-which determines what is usually referred to as labor supply at the extensive margin-into the behavior of the stand-in household requires behavior that need not replicate that of the average prime-age employed male. Heckman (1993) argues that the elasticity of participation decisions is large, and, in fact, most of the movement in aggregate hours worked is due to variations on the extensive margin.

In fact, if we want to model fluctuations of hours worked in the aggregate economy, the elasticity of labor supply should be estimated using aggregate data and not individual data. To the extent that hours worked in the model are less volatile that those in the data, this suggests that our implied labor supply elasticity may be smaller than it would be if we estimated this elasticity using the Spanish aggregate data that we are considering for the time period of interest. (This may not be the case, however, if workers are not able to determine their own hours worked because of involuntary unemployment or other sorts of rigidities.) 
Even within the context of estimation using microeconomic data, several papers show how the estimates of labor supply elasticities based on the variation of the working hours of prime-age employed males are biased downward. It is well known that women have higher labor supply elasticity than men. Moreover, Imai and Keane (2004) argue that in a framework with endogenous human capital accumulation, in particular, with learning by doing, the labor supply elasticity is 3.82. Domeij and Flodén (2006) have shown both theoretically and empirically that the presence of borrowing constraints biases the estimated individual labor supply elasticities downward.

Theoretical work focusing on indivisible labor, such as Hansen (1985) and Rogerson (1988), has shown that small (in their papers, zero) individual elasticities can aggregate to a big number (in their papers, infinite) depending on the particulars of the theoretical environment and the risk sharing arrangements available to people. Estimates of the labor supply elasticity that take into account the entire population and both the intensive and extensive margin generate numbers more in line with the implied elasticities using aggregate data. For example, Erosa et al. (2016) estimate a value of 1.75. In a life-cycle context, Rogerson and Wallenius (2009) find that taxes have large effects on aggregate labor supply, even if the labor supply elasticity at the individual level is as low as it is in microeconometric studies.

As a sensitivity analysis, we explore separable nonhomothetic utility to determine how sensible our results are to changes in the Frisch labor supply elasticity. Consider the utility function

$$
\sum_{t=1970}^{\infty} \beta^{t}\left(\frac{\gamma}{\rho_{c}}\left[\left(\frac{C_{t}}{\tilde{N}_{t}}\right)^{\rho_{c}}-1\right]+\frac{1-\gamma}{\rho_{\ell}}\left[\left(\frac{N_{t} \bar{h}-L_{t}}{N_{t}}\right)^{\rho_{\ell}}-1\right]\right) .
$$

This sort of utility function has been used for microeconometric estimation using individual data, as in Heckman (1993) and Browning et al. (1999), and for wealth distribution analysis, as in Castañeda et al. (2003). Our specification of utility in the stand-in household's problem (5) is the limiting case of the utility function (17) where both $\rho_{c}=0$ and $\rho_{\ell}=0$.

By varying $\rho_{\ell}$, we can vary the Frisch elasticity:

$$
\frac{u_{\ell}}{L u_{\ell \ell}}=\frac{1}{1-\rho_{\ell}}\left(\frac{N_{t} \bar{h}-L_{t}}{L_{t}}\right) .
$$

By setting $\rho_{\ell}=-4.768$, we obtain a Frisch elasticity of labor supply of about 0.75 , which is the sort of value favored by Chetty et al. (2011).

The value of $\rho_{c}$ controls whether hours worked rise or fall when income is increasing. We choose a value of $\rho_{c}=-0.5$, which implies that hours worked fall as income increases. King et al. (1988) show that, unless $\rho_{c}=0$, the utility function (17) is not consistent with the existence of a balanced growth path. Since our specification has no productivity growth after 2015 , however, we can ignore this potential problem.

Numerical experiments under this alternative specification of the utility function show that the evolution of taxes still matters. We calibrate the behavioral parameters of the model to 1970-2015 data as in the previous section and obtain $\beta=0.973$ and 


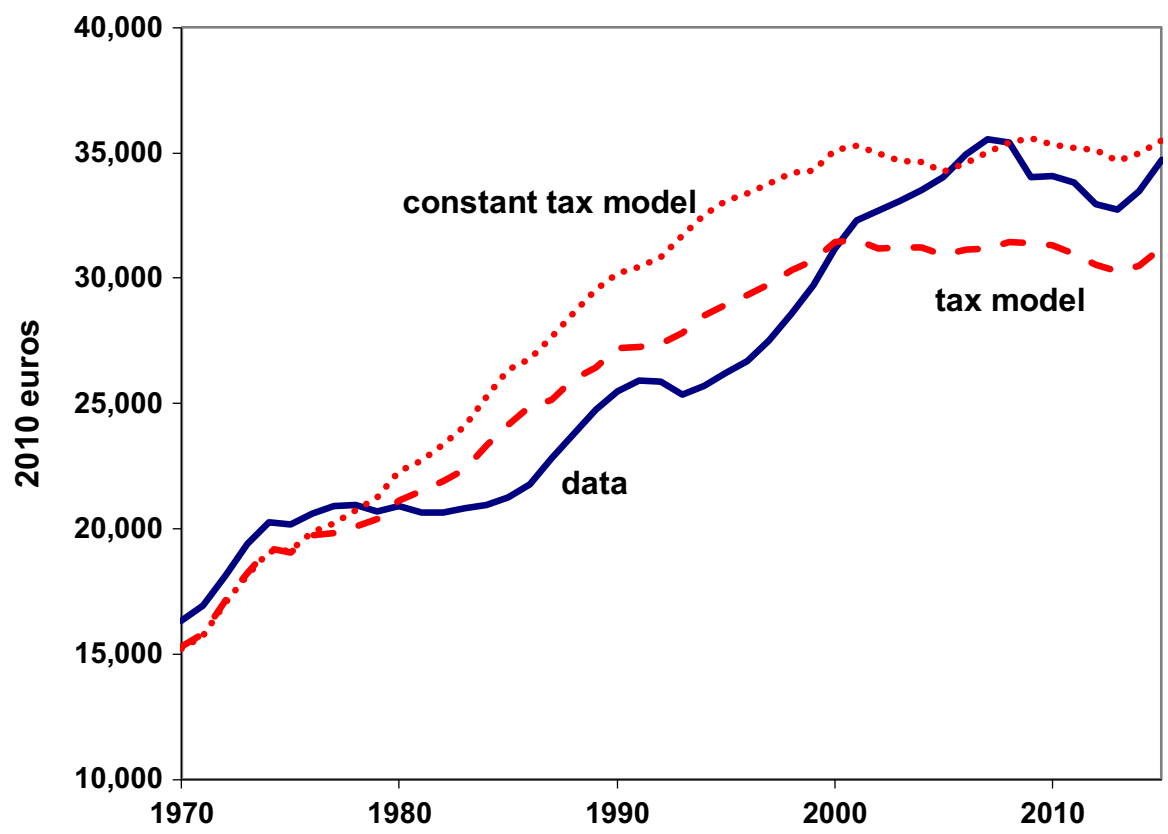

Fig. 10 GDP per working-age person with low labor supply elasticity

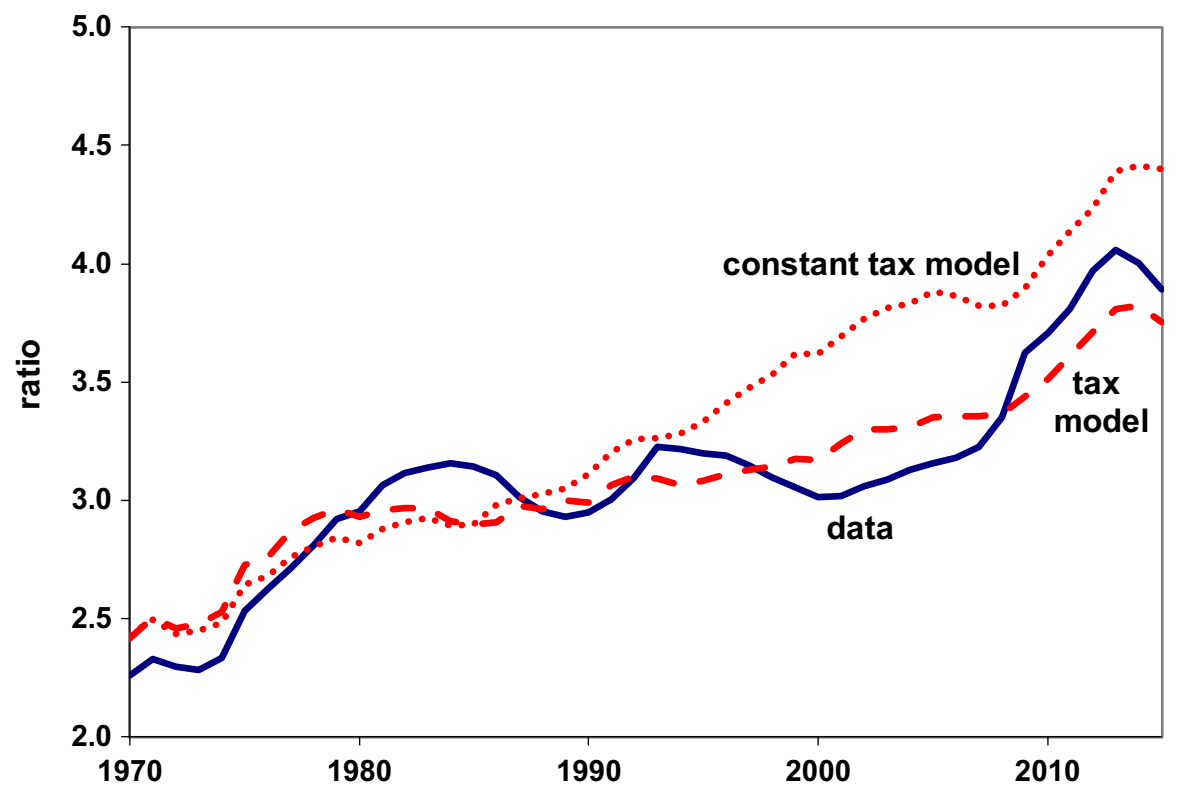

Fig. 11 Capital-output ratio with low labor supply elasticity 


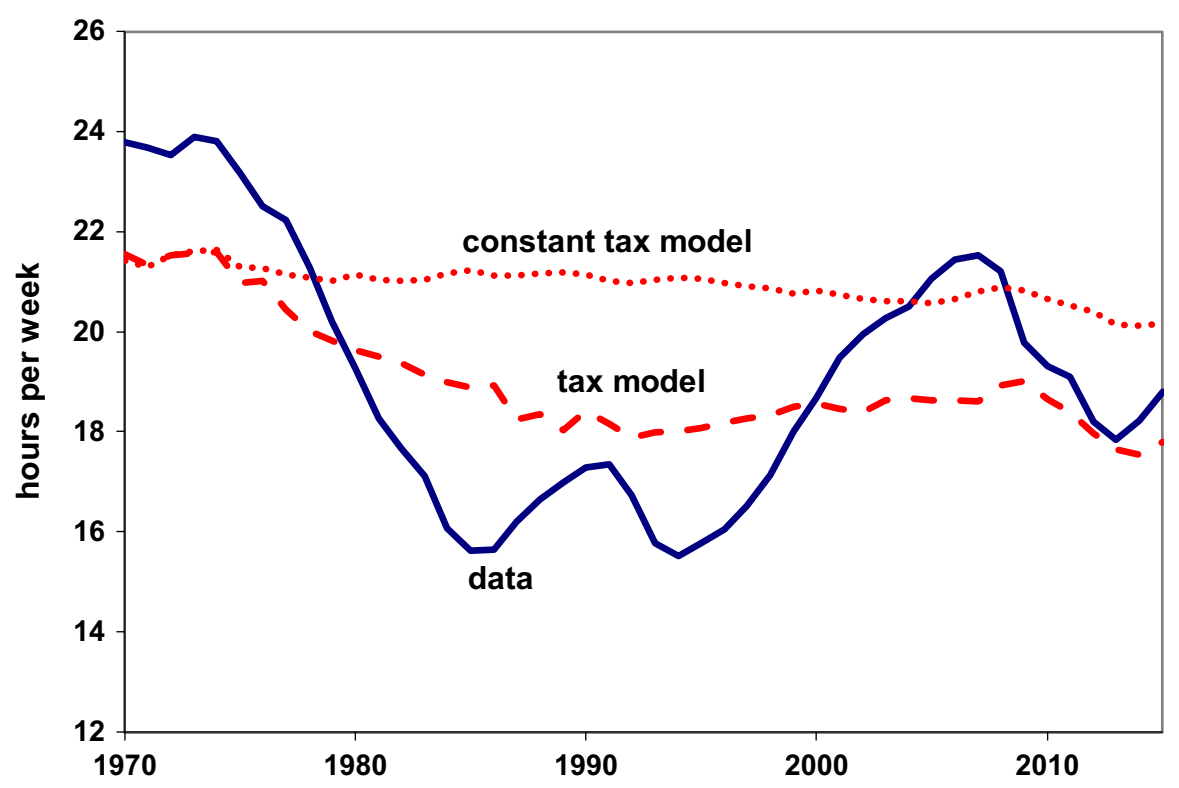

Fig. 12 Hours worked in the model with low labor supply elasticity

$\gamma=0.504$. Notice that, since we have changed the functional form of the stand-in household's utility function, these parameters are not easily comparable to those used in the previous sections.

Figures 10,11 and 12 report our results for the case with a low labor supply elasticity for both the case with taxes evolving as in Fig. 2 and with government consumption evolving as in Fig. 3, and the counterfactual with constant taxes and government consumption.

The results in Fig. 12 show that the model with increasing taxes performs better in explaining hours worked than the model with constant taxes. In particular, while hours worked per working-age person fall by $21.0 \%$ from 1974 to 2015 in the data, in the model with increasing taxes, they fall by $17.5 \%$. In contrast, in the model with constant taxes, hours worked per working-age person fall by only $6.8 \%$. Although the performance of the model with low labor supply elasticity in capturing the fall in hours worked in Spain in Fig. 12 is not as impressive as the results for the model with a higher labor supply elasticity, reported in Figs. 6 and 9, the results still show the importance of increasing taxes in accounting for Spanish labor market outcomes.

\section{The role of the lack of productivity growth}

A striking feature of the growth accounting for Spain reported in Fig. 1 is that productivity has been flat since 1995. To understand the impact of the lack of productivity growth on labor market outcomes, we ask the model what would have happened if TFP after 1994 had grown at the same average rate as it had grown from 1970 to 


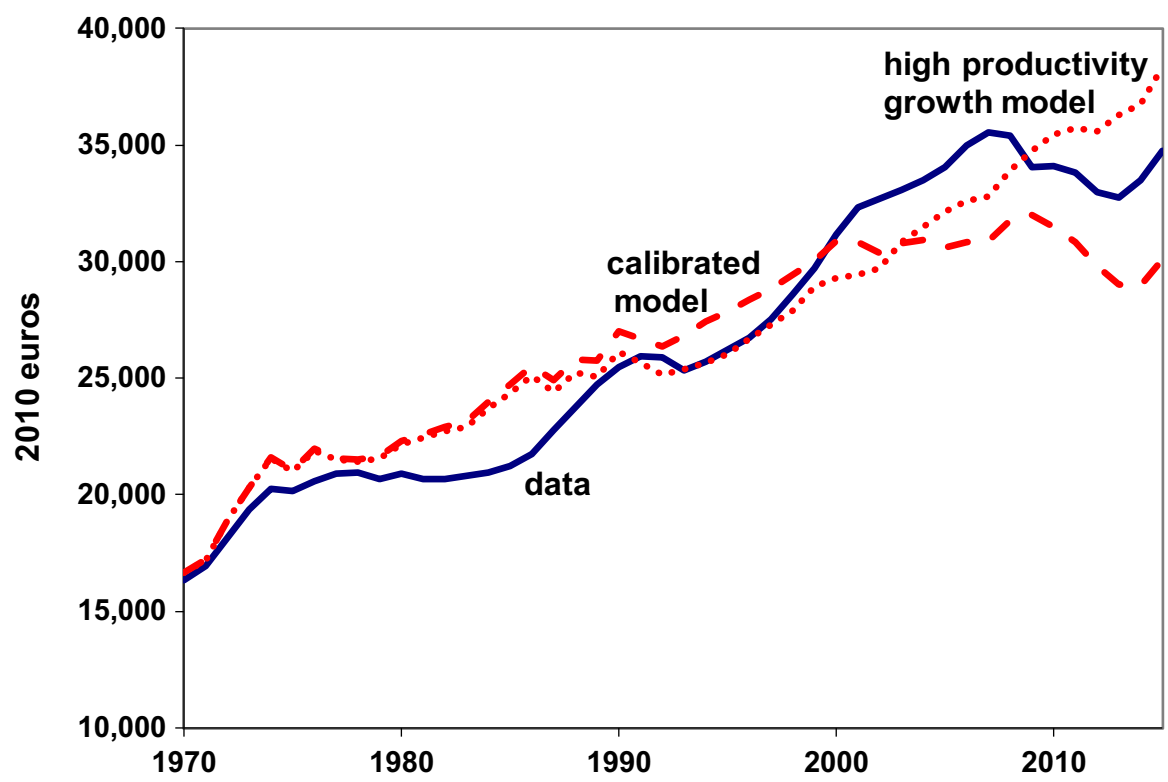

Fig. 13 GDP per working-age person with high TFP growth

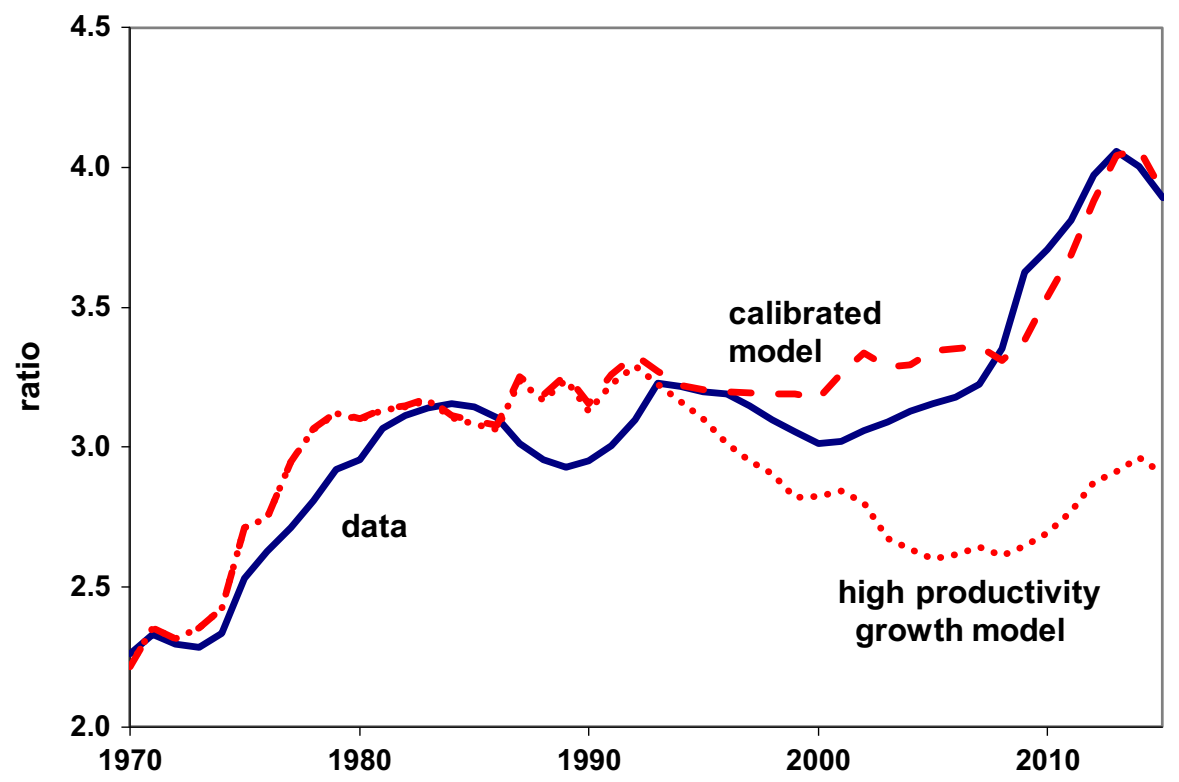

Fig. 14 Capital-output ratio with high TFP growth

1994: $1.22 \%$ per year. Again, we calibrate the behavioral parameters of the model to the data from the entire period 1970-2015, as in Sect. 7. We refer to the model with TFP calibrated to the data as the calibrated model rather than as the benchmark model 


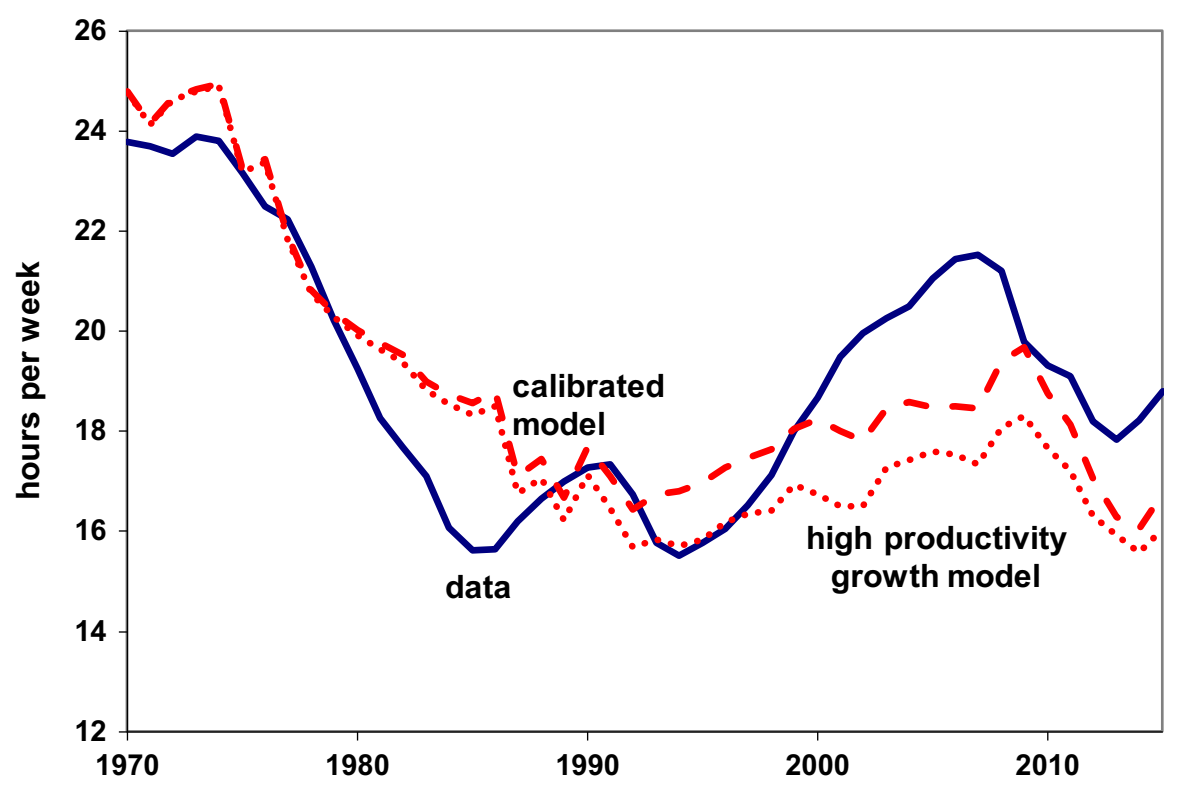

Fig. 15 Hours worked in the model with high TFP growth

because the benchmark model in Sect. 6 has behavioral parameters calibrated to data from 1970 to 1974.

The results reported in Figs. 13, 14 and 15 show that the lack of productivity growth over the period 1995-2015 is very important for understanding the evolution of GDP per working-age person and the capital-output ratio, but that its impact on hours worked is small.

The results in Fig. 15 suggest that there was little relation between the changes in productivity and changes in hours worked in Spain over our period of interest, 19752015. Nonetheless, the timing of changes in productivity and changes in hours suggests the possibility of an endogenous relation between the two. In particular, notice that, in the growth accounting in Fig. 1, productivity stagnates when hours worked boom during the period 1994-2007. It is possible that the labor market reforms that allowed greater use of temporary contracts and encouraged this boom in hours also encouraged hiring less productive workers, which led to the drop in productivity. This possibility is worth exploring further.

\section{Concluding remarks}

In this paper, we have argued that the trend of aggregate hours worked in Spain is consistent with neoclassical growth theory given the observed trends of taxes and government consumption. The impact of increases in taxes on hours worked is dampened if the labor supply elasticity is substantially lower than that typically used in macroeconomic research but is not eliminated. 
Our model underpredicts the magnitude of large fluctuations in hours worked. Recent research suggests that the institutional arrangements of the Spanish labor market imply a larger reaction of hours worked or employment to shocks. See Bentolila et al. (2012) for an analysis of the differential response of France and Spain to the recent recession, and Jimeno and Santos (2014) for a comprehensive analysis of the Spanish experience during the last recession in 2008-2009.

In contrast to the evolution of taxes, the lack of TFP growth in Spain since 1994 does not generate a substantial impact on the evolution of hours worked in our model.

Open Access This article is distributed under the terms of the Creative Commons Attribution 4.0 International License (http://creativecommons.org/licenses/by/4.0/), which permits unrestricted use, distribution, and reproduction in any medium, provided you give appropriate credit to the original author(s) and the source, provide a link to the Creative Commons license, and indicate if changes were made.

\section{References}

Alesina AF, Glaeser EL, Sacerdote B (2005) Work and leisure in the U.S. and Europe: why so different? In: Gertler M, Rogoff K (eds) NBER macroeconomics annual 2005, vol 20. MIT Press, Cambridge, pp 1-64

Bentolila S, Bertola G (1990) Firing costs and labour demand: how bad is Eurosclerosis? Rev Econ Stud 57:381-402

Bentolila S, Cahuc P, Dolado JJ, Le Barbanchon T (2012) Two-tier labour markets in the Great Recession: France versus Spain. Econ J 122:F155-F187

Bergoeing R, Kehoe PJ, Kehoe TJ, Soto R (2002) A decade lost and found: Mexico and Chile in the 1980s. Rev Econ Dyn 5:166-205

Blanchard OJ, Summers LH (1986) Hysteresis and the European unemployment problem. In: Fischer S (ed) NBER macroeconomics annual 1986, vol 1. MIT Press, Cambridge, pp 15-90

Browning M, Hansen LP, Heckman JJ (1999) Micro data and general equilibrium models. In: Taylor JB, Woodford M (eds) Handbook of macroeconomics, vol 1, Part A. Elsevier, Amsterdam, pp 543-633

Castañeda A, Díaz-Giménez J, Ríos-Rull JV (2003) Accounting for the U.S. earnings and wealth inequality. J Polit Econ 111:818-857

Chari VV, Kehoe PJ, McGrattan ER (2007) Business cycle accounting. Econometrica 75:781-836

Chetty R, Guren A, Manoli D, Weber A (2011) Are micro and macro labor supply elasticities consistent? A review of evidence on the intensive and extensive margins. Am Econ Rev 101:471-475

Cole HL, Ohanian LE (1999) The Great Depression in the United States from a neoclassical perspective. Fed Reserve Bank Minneap Q Rev 23:2-24

Conesa JC, Kehoe TJ, Ruhl KJ (2007) Modeling great depressions: the depression in Finland in the 1990s. Fed Reserve Bank Minneap Q Rev 31:16-44

Diaz A, Franjo L (2016) Capital goods, measured TFP and growth: the case of Spain. Eur Econ Rev 83:19-39

Domeij D, Flodén M (2006) The labor-supply elasticity and borrowing constraints: why estimates are biased. Rev Econ Dyn 9:242-262

Erosa A, Fuster L, Kambourov G (2016) Towards a micro-founded theory of aggregate labor supply. Rev Econ Stud 83:1001-1039

Fernandez de Cordoba G, Kehoe TJ (2000) Capital flows and real exchange rate fluctuations following Spain's entry into the European Community. J Int Econ 51:49-78

Garcia-Santana M, Moral-Benito E, Pijoan-Mas J, Ramos R (2016) Growing like Spain: 1995-2007. In: CEPR Discussion Paper 11144

Gouveia M, Strauss RP (1994) Effective federal individual income tax functions: an exploratory empirical analysis. Natl Tax J 47:317-339

Hansen GD (1985) Indivisible labor and the business cycle. J Monetary Econ 16:309-327

Heckman JJ (1993) What has been learned about labor supply in the past twenty years? Am Econ Rev 83:116-121 
Imai S, Keane MP (2004) Intertemporal labor supply and human capital accumulation. Int Econ Rev 45:601-641

Jimeno JF, Santos T (2014) The crisis of the Spanish economy. SERIEs J Span Econ Assoc 5:125-141

Kehoe TJ, Prescott EC (2002) Great depressions of the 20th century. Rev Econ Dyn 5:1-18

King RG, Plosser CI, Rebelo ST (1988) Production, growth and business cycles: I. the basic neoclassical model. J Monetary Econ 21:195-232

Ljungqvist L, Sargent TJ (1998) The European unemployment dilemma. J Polit Econ 106:514-550

Mendoza EG, Razin A, Tesar LL (1994) Effective tax rates in macroeconomics: cross-country estimates of tax rates on factor incomes and consumption. J Monetary Econ 34:297-323

Mulligan CB (2005) Public policies as specification errors. Rev Econ Dyn 8:902-926

Ohanian L, Raffo A, Rogerson R (2008) Long-term changes in labor supply and taxes: evidence from OECD countries, 1956-2004. J Monetary Econ 55:1353-1362

Prescott EC (2004) Why do Americans work so much more than Europeans? Fed Reserve Bank Minneap Q Rev 28:2-13

Rogerson R (1988) Indivisible labor, lotteries and equilibrium. J Monetary Econ 21:3-16

Rogerson R, Wallenius J (2009) Micro and macro elasticities in a life cycle model with taxes. J Econ Theory 144:2277-2292 